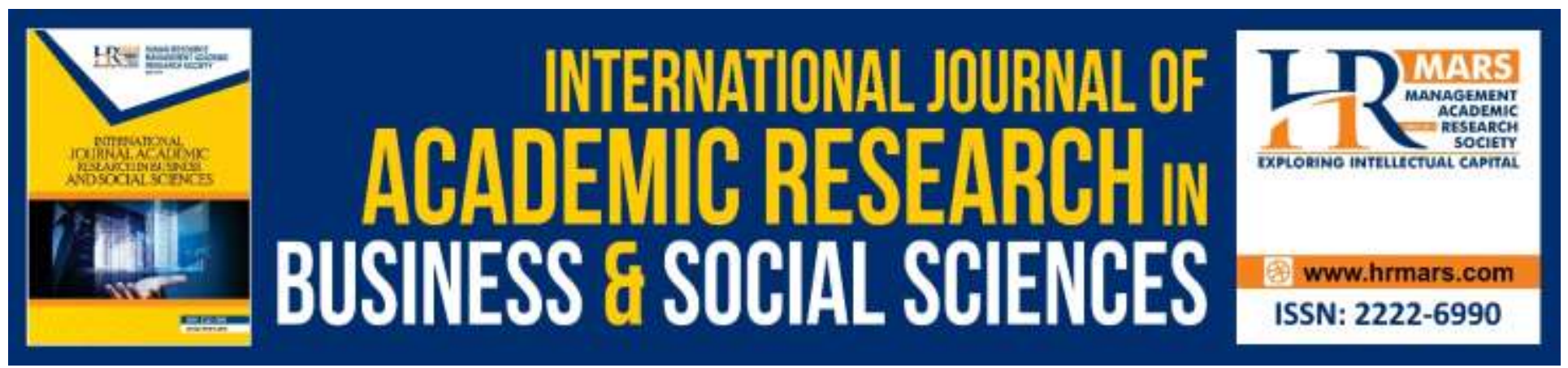

\title{
The Social and Communication Skills Difficulties among Learners with Autism Spectrum Disorder
}

\author{
Shirley N. Cerbo, Norfishah Mat Rabi
}

To Link this Article: http://dx.doi.org/10.6007/IJARBSS/v9-i6/6077

DOI: 10.6007/IJARBSS/v9-i6/6077

Received: 10 April 2019, Revised: 17 May 2019, Accepted: 04 June 2019

Published Online: 29 June 2019

In-Text Citation: (Cerbo \& Rabi, 2019)

To Cite this Article: Cerbo, S. N., \& Rabi, N. M. (2019). The Social and Communication Skills Difficulties among Learners with Autism Spectrum Disorder. International Journal of Academic Research in Business and Social Sciences, 9(6), 1152-1162.

\section{Copyright: (C) 2019 The Author(s)}

Published by Human Resource Management Academic Research Society (www.hrmars.com)

This article is published under the Creative Commons Attribution (CC BY 4.0) license. Anyone may reproduce, distribute, translate and create derivative works of this article (for both commercial and non-commercial purposes), subject to full attribution to the original publication and authors. The full terms of this license may be seen

at: http://creativecommons.org/licences/by/4.0/legalcode

Vol. 9, No. 6, 2019, Pg. $1152-1162$

http://hrmars.com/index.php/pages/detail/IJARBSS

JOURNAL HOMEPAGE

Full Terms \& Conditions of access and use can be found at http://hrmars.com/index.php/pages/detail/publication-ethics 


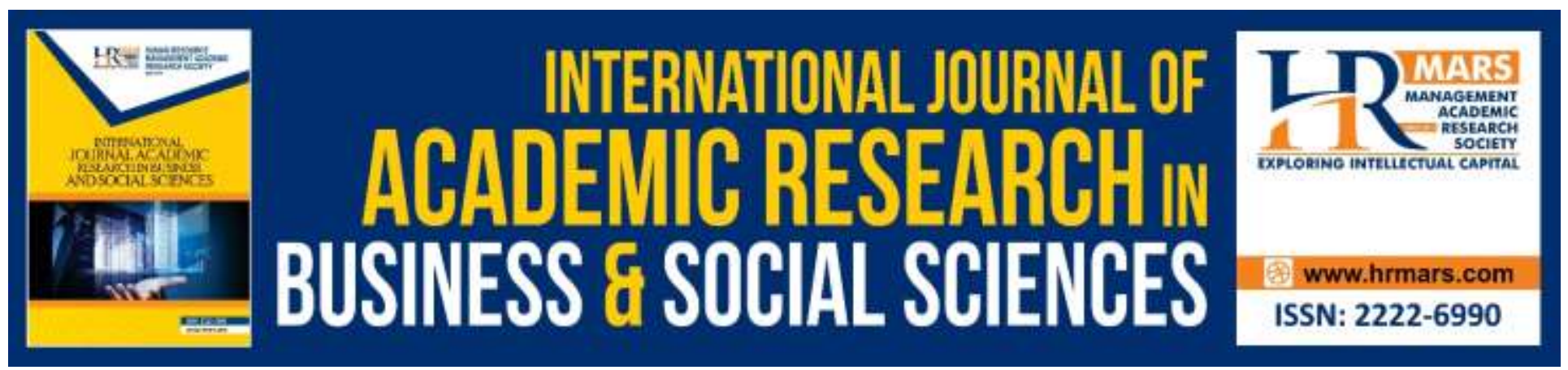

\title{
The Social and Communication Skills Difficulties among Learners with Autism Spectrum Disorder
}

\author{
Shirley N. Cerbo ${ }^{1}$, Norfishah Mat Rabi² \\ ${ }^{1}$ Faculty of Education Sciences, Philippine Normal University, Philippines \\ ${ }^{2}$ Faculty of Human Development, Universiti Pendidikan Sultan Idris, Malaysia
}

\begin{abstract}
The purpose of this study is to investigate the social and communication skills difficulties among identified learners with ASD in the Philippines. Objectives of the study are to identify what are the social and communication characteristics of the children with Autism Spectrum Disorder (ASD) and to identify the effect of their social and communication difficulties in the learning process. The case study was conducted at Jose Fabella Memorial School (JFMS), Mandaluyong City, Philippines and participants were selected purposively involving six learners with ADS, their parents and their teachers. The data collection period is for five months. Data were collected through interviews, observations, and checklist analysis. The research instruments used were checklist, interview questions and field notes. Data were analyzed using descriptive methods. Inter-rater checklist results were used for document analysis. Thematic analysis was used to examine the collected data from the interviews, the observations, and the checklist. Findings showed that the six children with ASD demonstrated degrees of similarities and differences in their social and communication behaviors. Their social skills difficulties are in the aspects of showing interest in joining other children in games and other activities; showing interest in people; initiative to join others in games or other activities; choice of solitary activity over activity that involves interaction with others; saying or exhibiting socially inappropriate things like screaming and hurting others; and the inability to readily exchange social smile. Their communication skills difficulties are in the aspects of initiative in talking with others; asking question; taking turn in conversation; self-expression using oral language; clarity in speaking; showing eye contact; loudness of voice in speaking and showing facial expression. The social and communication skills difficulties of the learners with ASD have favorable effects on their learning process. The implication of the study showed that the learning experiences of the children with ASD are hampered and are not maximized due to their difficulties in social and communication skills. In conclusion, classroom learning environment must be improved and appropriate intervention be conducted to address their difficulties. Teachers can make the classroom activities more inclusive to develop a feeling of acceptance and belongingness to this group of learners. Differentiated instructions must be applied so as to address the needs of both the typical and atypical learners.
\end{abstract}


INTERNATIONAL JOURNAL OF ACADEMIC RESEARCH IN BUSINESS AND SOCIAL SCIENCES Vol. 9, No. 6, June, 2019, E-ISSN: 2222-6990 @ 2019 HRMARS

Keywords: Autism Spectrum Disorder, Social Skills, Communication Skills.

\section{Introduction}

The Individuals with Disabilities Education Act (IDEA) identified deficiencies in social and communication skills as an early marker of individuals with Autism Spectrum Disorder (ASD). As a set of neurodevelopmental disorders, ASD includes autistic disorder, Asperger syndrome, and pervasive developmental disorder not otherwise specified (PDD-NOS). Silverman (2012) stated that autism is a developmental disorder that involves "qualitative impairments" in the aspects of language, communication and social relationships that manifest in combination with "restricted, repetitive and stereotyped patterns of behavior". Learners under this category are characterized by abnormalities in any or all of the following domains: language use, reciprocal social interactions, and/or a pattern of restricted interests or stereotyped behaviors (Newschaffer et al., 2012).

According to the Autism and Developmental Disorder Monitoring Network (2014), prevalence of incidence of ASD is on the rise and the number of learners having been classified with ASD have increased ten times from 1995 to 2014 that it is possible to have learners with ASD in every classroom (Anderson et al., 2018). Autism Society of the Philippines (2012) reported that according to the United Nations Organization, $1 \%$ of the global population is on autism spectrum. In the Philippines, close to a million of the approximately 102 million population deal with autism disorder (Autism Society of the Philippines, 2016). The condition affects the relationship and interaction of these learners to cope with their typically developing peers (Bailey, 2012). In the study of Bauminger-Zviely (2013), difficulties experienced by learners with ASD were identified. It was mentioned that the demeanor and awkward movements of learners with autism make them easy targets for bullying. The typicallydeveloping classmates find them aloof and disinterested.

\section{Literature Review}

Many of the learners under the ASD category have average to above-average mental functioning, as in the case of those with Asperger or high functioning autism. Some of them were not properly assessed and evaluated as having ASD because their intellectual capabilities are equal with or even higher than the neurotypicals. This enables them to be mainstreamed in regular schools and learn side by side with the typically developing children. However, their behaviors manifest the same deficits in communication skills and social functioning as those in the other types of ASD. Notable concern is on the area of taking turns in conversation or reciprocal communication. It also involves nonverbal communication used in social interaction like gestures, facial expression, eye contact, and/or body posture (DSM 5, American Psychiatric Association, 2013).

According to Daraeea et al., (2016), social skills are one of the essential contributing factors in determining the success or failure of a person in life. Teaching the right social skills and providing opportunities for social interactions enable the students to apply strategies for socializing in different social contexts. Social skills involve the ability to communicate, relate, and form emotional connections with one another (Bailey and Montgomery, 2012). These enable persons to interact, relate with and collaborate with others. Persons with autism have problems with social and communication skills because they lack the "theory of the mind" and are unable to imagine other 
people's mental states (Silverman, 2012). They have the inability to make inference to the different mental states of people including their beliefs, emotions, opinions and intents. Forming close bonds and relationship with others is difficult because of the deficiency in understanding other persons' reaction, expression, or emotion. They find it hard to empathize. Verbal communication which involves turn-taking and reciprocal communication is very limited among learners with ASD. Echolalia, the repetition of a phrase or a sentence uttered by another, marks the usual pattern of reaction. There is impairment in the use of nonverbal behaviors which includes a lack of, or an excessive eye-to-eye gaze, inappropriate facial expression, unnatural body postures, and stereotyped repetitive actions or mannerism (Murdymooto et al., 2017).

Majid (2015) defines communication skills as the ability to convey information by means of exchanging ideas, intentions, attitudes, emotions, expectations, perceptions, or commands through speaking, using gestures, body language or by writing. He further noted that effective communication takes place when its desired purpose which could include eliciting action, creating understanding or giving information has been achieved. Nonverbal communication as described by Venu \& Reddy (2016), is the transmission of meaning through non-word messages. According to Neisworth \& Wolfe (quoted by Scott, Clark, \& Brady, 2000:201), between $28 \%$ and $61 \%$ of children with ASD are marked by a lack of functional speech. Persons with ASD have difficulties in both the use of verbal and nonverbal means of expressing themselves. Some persons with ASD may be unable to communicate using the spoken language. For others who are able speak, language may be strange, repetitive or disordered. Dialogic conversation is oftentimes substantially restricted (Hannell, 2006).

Social and communication skills are important for functioning in a variety of settings (Campbell et al., 2010). These skills enable a child to be accepted. Failure to develop these two essential skills could lead to problems in their present and the future environments. The lack of social competence and the deficiencies in communication skills adversely affect the quality of lives and the independence of learners with ASD. The inability for social interaction makes learners with ASD the object of teasing, victimization and bullying by their peers, especially in high school where social differences become more evident and important within peer groups. Not knowing how to socialize and interact with others, they continue to exist in isolation. Social deficits lead learners with ASD to become reclusive even if they long to have friends (Murdymootoo et al., 2017).

The Social Learning Theory by Albert Bandura (Mc. Leod, 2012) affirms that behavior is learned from the environment, within a social context, through the process of learning by observation. Bandura (1976) posited that social skills cannot be taught in isolation. He postulated that people learn from one another by observation, imitation, and modeling. Teaching new behaviors; influencing the frequency of behaviors that were previously acquired; and increasing the frequency of manifesting similar behaviors are some of the effects of modeling. Observational learning, another term for social learning theory, takes place when an observer's behavior changes after viewing the behavior of a model. Social learning can take place within the classroom. Modeling of appropriate behavior and new skills could come from the teacher and the typically developing classmates. 
INTERNATIONAL JOURNAL OF ACADEMIC RESEARCH IN BUSINESS AND SOCIAL SCIENCES Vol. 9, No. 6, June, 2019, E-ISSN: 2222-6990 (C) 2019 HRMARS

\section{Methodology}

This case study examines specifically the social and communication skills difficulties of learners with ASD. Purposive sampling is used in this study. The sample of six learners with ASD is used in the study. Data were collected through interviews, observations and document analysis. Individual interview sessions were conducted to obtain qualitative data with the teachers and the parents of the learners with ASD as respondents. Instruments used in collecting data are interview questions, checklist and field notes. The checklist used in collecting data was adapted from The Autism Checklist by Glynis Hannell (2006). Documents referenced are the individual school evaluation forms of the six sample. The case study was analyzed and reported descriptively and supported by reference statistics.

\section{Results}

The findings refer to the social and communication skills difficulties of learners with autism and the effect of such in the samples' learning process. Result is reported in three main areas: (i) social skills difficulties of learners with ASD, (ii) communication skills of learners with ASD, (iii) effects of the social and communication skills difficulties in the learning process.

1) Social skills difficulties of learners with ASD

Social skills difficulties are the negative behaviours manifested by the learners with ASD in the study which negatively affect their learning process.

Table 1. Social Skills Difficulties of Learners with ASD

\begin{tabular}{|l|c|c|c|c|c|}
\hline \multicolumn{1}{|c|}{ Identified Behaviours } & \multicolumn{2}{c|}{$\begin{array}{c}\text { Number of times the Behaviour is } \\
\text { Mentioned/Manifested }\end{array}$} & Total & Frequency \\
\hline & Interview & Observation & Checklist & & \\
\hline $\begin{array}{l}\text { Is not interested in joining other } \\
\text { children in games or group activities }\end{array}$ & 14 & 10 & 4 & 28 & $22.58 \%$ \\
\hline $\begin{array}{l}\text { Needs prompting to join others in } \\
\text { games or other activities }\end{array}$ & 21 & 1 & 4 & 26 & $20.97 \%$ \\
\hline $\begin{array}{l}\text { Does not readily exchange social } \\
\text { smile }\end{array}$ & 5 & 1 & 1 & 7 & $5.65 \%$ \\
\hline $\begin{array}{l}\text { Does not attempt to make friends } \\
\text { with others }\end{array}$ & 5 & 2 & 5 & 12 & $9.68 \%$ \\
\hline Is not interested in people & 9 & 2 & 5 & 16 & $12.90 \%$ \\
\hline Likes solitary activities & 23 & 1 & 1 & 25 & $20.16 \%$ \\
\hline $\begin{array}{l}\text { Says and does socially inappropriate } \\
\text { things as screaming and hurting } \\
\text { others }\end{array}$ & & & & & 10 \\
\hline
\end{tabular}

Table 1 shows that the behavior of not having interest in joining other children in games and group activities got a frequency of $26.92 \%$ in the three data sources. This finding strongly shows that most of the respondents have observed the manifestation of the given behavior among the six learners with ASD. A frequency of $22.11 \%$ indicates that the second behavior that was strongly 
INTERNATIONAL JOURNAL OF ACADEMIC RESEARCH IN BUSINESS AND SOCIAL SCIENCES Vol. 9, No. 6, June, 2019, E-ISSN: 2222-6990 @ 2019 HRMARS

manifested by the participants is that of saying and doing socially inappropriate things as screaming and hurting others. The participants need prompting before they would join others in games or activities has a frequency of $20.19 \%$. Two of the identified behaviors have the same frequency of $8.65 \%$. The lack of interest in people and preference for solitary activities both affirm the reclusive tendencies of persons with ASD. The last two behaviors which are likewise related, have a similar frequency of $6.73 \%$. The learners do not make any attempt to befriend others and they do not readily exchange social smile.

2) Communication Skills Difficulties of Learners with ASD Communication skills difficulties refer to the behaviours that the learners in the study have deficiency in and which negatively affect the learning process.

Table 2. Communication Skills Difficulties of Learners with ASD

\begin{tabular}{|l|c|c|c|c|c|}
\hline Identified Behaviours & \multicolumn{3}{|c|}{ Number of times the Behaviour is } & Total & Frequency \\
\hline & Interview & Observation & $\begin{array}{c}\text { Observation } \\
\text { Checklist }\end{array}$ & & \\
\hline $\begin{array}{l}\text { Cannot initiate to talk with } \\
\text { others/Needs prompting to } \\
\text { respond orally }\end{array}$ & 18 & 1 & & 19 & $15.97 \%$ \\
\hline Cannot ask question & 7 & 1 & 2 & 10 & $8.40 \%$ \\
\hline $\begin{array}{l}\text { Has significant difficulties taking } \\
\text { turn in conversation/ Lacks } \\
\text { reaction in conversation }\end{array}$ & 5 & 1 & 5 & 11 & $9.24 \%$ \\
\hline $\begin{array}{l}\text { Has difficulty expressing self } \\
\text { orally/Does not talk }\end{array}$ & 10 & 2 & 2 & 14 & $11.77 \%$ \\
\hline Lacks clarity in speaking & 7 & 1 & 1 & 9 & $7.56 \%$ \\
\hline Has no eye contact & 6 & 2 & 5 & 13 & $10.93 \%$ \\
\hline Does not respond to question & 24 & 1 & 2 & 27 & $22.69 \%$ \\
\hline Voice is too soft & 8 & 1 & & 9 & $7.56 \%$ \\
\hline $\begin{array}{l}\text { Does not show change in facial } \\
\text { expression }\end{array}$ & 4 & 1 & 2 & 7 & $5.88 \%$ \\
\hline
\end{tabular}

Table 2 illustrates the identified communication skills deficits of the six participants. The three data sources show that the inability to respond to question is the behaviour that was repeated the most number of times. It has a frequency of $22.69 \%$. This behaviour is closely related to other 
behaviours identified which include the inability to talk with others without prompts or the necessity of being prompted so as to respond orally. This has a frequency of $15.97 \%$. Similarly, $11.77 \%$ frequency was obtained in the manifestation of the learners with ASD's difficulty in expressing themselves orally or their inability to talk. A frequency of $10.93 \%$ indicates that the learners lack eye contact. Although some of the learners are able to utter very limited responses occasionally, they have significant difficulties taking turn in conversation and generally lack reaction in conversation. This finding is indicated by the $9.24 \%$ frequency of manifestation. In connection, $8.40 \%$ frequency shows that they cannot ask question. Two related behaviors, a lack of clarity and a lack of volume of the voice in speaking both have a frequency of $7.56 \%$. The learners with autism also do not show change in facial expression. This behavior has a frequency of $5.88 \%$.

3) Effects of the social and communication skills difficulties in the learning process

The learning process of the learners with ASD in the study and are in regular classrooms learning together with their neurotypical classmates are affected by their social and communication skills difficulties. Reading, writing, and following directions are actions that the learners are able to do, yet they have asynchronous levels of coping with the learning instructions. Three of the samples are able to work on individual tasks assigned by the teachers at a rate faster than their classmates. The waiting process for the whole class to finish the task they have completed cause boredom to set in. This brings about behaviors like walking around the room aimlessly or producing unintelligible sounds that disrupt the class.

Comprehending the lesson is not a problem to one of the learners, yet the lack of clarity in speaking and the extremely soft volume of the learner's voice negatively affect the learner's performance in the classroom. The teacher seldom calls the learner with ASD to recite since the class will not be able to hear what the learner is saying. So it is only through the written outputs that the learner is able to show fast understanding of the lesson.

The learners' level of tolerance in the classroom is affected by their condition. Three of the children have no tolerance for classroom noise. Transition for the next class could cause the chattering of some learners. During class discussion, over enthusiasm to get the teacher to call them during class recitation could also produce noise. The noise causes the learners with ASD to retreat in their own world to shut out overstimulation. Different coping behaviours were manifested like crying; closing the eyes; putting palms on both ears; and putting the mobile phone near the ear to listen to music.

Typically developing classmates react to the atypical ones in different ways. The lack of social gaze among the learners with ASD gives an impression on the other children that they are not interested. Due to the silence of these learners, they were not attended to by the neurotypicals unless they are assigned by the teacher to assist their classmates. This limits their interaction to simply providing support to the needs of a classmate with ASD. The interaction does not lead to the development of acquaintance and friendship since typically developing classmates were randomly assigned, as the need arises, to provide help. 
Bullying is another concern experienced by learners with ASD. Taking advantage of their condition, other children get things from inside the bag of the child with autism, or put trash like crumpled, used paper inside the bag without the person's knowledge. Extortion or asking money from the atypical child who readily gives in is also experienced by one of the children.

Strong measures to stop any form of bullying are being implemented by the school where the learners are enrolled. Protection of all the learners, both typical and atypical are foremost in their agenda. Policy related to this is being implemented. This results for only occasional incidents of bullying that take place and are attended to right away.

Strategies and teaching methodology that most teachers of the learners with ASD in the study use primarily are lecture and big group discussion. Collaborative activities where the learners are engaged in interactive activities with others through small group activities are used by only two of the teachers. Different roles were given by the teachers where learners with ASD are either supported by their group mates, or they provide support to the neurotypical classmates. The activities enable the learners with ASD to have direct and purposeful interaction with their classmates.

Classroom management is occasionally adversely affected by the condition of the learners with ASD. Except for the occasional meltdowns, where the atypical learners display inappropriate behaviours like screaming and hurting others, the teachers affirm the overall lack of disciplinary concerns about the learners with ASD who generally sit quietly throughout the class period, thus not causing any disruption in the class. The children with ASD were each seated alone to avoid triggers that lead to tantrums. Additional seatwork is given to atypical learners when they complete the task ahead of their typically developing classmates to avoid manifestation of unacceptable behaviors.

\section{Discussion}

The study identified the social and communication skills deficits of the learners with ASD and the effects of their skills deficits in the learning process. Difficulties in the area of social skills have been considered as the distinguishing marks of children with ASD (American Psychiatric Association, 2013; Pickard \& Ingersoll, 2015). Socialization skills deficits of the learners in the study include not having interest in joining other children in games and group activities; saying and doing socially inappropriate things as screaming and hurting others; the need for prompting before joining others in games or activities; a lack of interest in people and a preference for solitary activities; and the absence of any attempt to befriend others and to readily exchange social smile. Learners with autism have problems in communicating and interacting with others Murdymootoo (2017). Difficulties in communication skills include the inability to respond to question; inability to talk with others without prompts or the necessity of being prompted so as to respond orally; difficulty in expressing themselves orally or the general inability to talk; the absence of eye contact; significant difficulties taking turn in conversation and the absence of reaction in conversation; inability to ask question; a lack of clarity and a lack of volume of the voice in speaking; and a lack of change in facial expression. 
Gustaven (2017) pointed out that the learners' social behavior could either promote or hinder learning. The sociocultural theory of Lev Vygotsky (1998) affirms that social interaction leads to changes in the behaviour of individuals. Learning takes place when there is a change in behavior. Social Interaction with others is needed to be developed by the learners with ASD because it affects their learning in school. It is through contact with others that they get to learn academically. Appropriate behaviors and some skills can be learned by imitation of a model (Bandura, 1976). The model could either be the teacher or the other children in the class. A lack of interaction with others is one of the challenges that affect the children's functioning in school (Anderson et al., 2018).

The unnatural characteristics of learners with ASD like a lack of appropriate expression on the face and lack of the use of natural gestures make them the object of teasing and bullying in the classroom. The difficulties manifested by the samples cause them to be often set aside or neglected. A truly inclusive classroom environment that respects the learners with special educational needs can benefit this group of learners (Lai et al., 2013). Closer relations between learners with ASD and their teachers and classmates promote more understanding of the plight of learners with ASD. In the study conducted by Mc Mahon et al., (2012), it was suggested that patterns of conversation or interaction that have the potential for the development of friendship must be encouraged in the school or in the home. Classroom activities must affirm the acceptance of the learners in the classroom. Macnamara, (2015), mentioned in his study that learners must feel that they are included in a classroom that is learner - centered.

Teacher factor is also important in promoting the learning of children with ASD. Sufficient training for teachers in handling this group of atypical learners is essential. Efforts have to be exerted to make the classroom more inclusive and more child - centered so as to address the needs of both the neurotypicals and the atypical learners. Aside from lectures, teachers could make use of other strategies to encourage more participation of all the learners. Cooperative learning activities, peertutoring, and other strategies for differentiated instruction must be used by the teachers to facilitate learning of the students (Rabi et al., 2018). Activities that encourage the use of verbal exchange among learners could help address the learners' skill deficits. Through social learning, learners with ASD are able to learn by imitation of modeled appropriate behavior or skill.

Interventions that would effectively address the social and communication skills deficits of learners with ASD are needed (Vidal, 2012). These will provide support for a more positive and productive academic learning.

\section{Conclusion}

Children with autism, unlike their typically developing peers, do not follow all the milestones of development as regards growth and maturation. Specific to this is their delay in the social and communication aspects. Social and communication skills difficulties adversely affect the learning process of learners with ASD. It is recommended that appropriate intervention be conducted to address their difficulties. Teachers can make the classroom activities more inclusive to develop a feeling of acceptance and belongingness to this group of learners. 
INTERNATIONAL JOURNAL OF ACADEMIC RESEARCH IN BUSINESS AND SOCIAL SCIENCES

Vol. 9, No. 6, June, 2019, E-ISSN: 2222-6990 @ 2019 HRMARS

\section{Corresponding Author}

Shirley N. Cerbo

Faculty of Education Sciences, Philippine Normal University,

Manila, Philippines

Email: cerbo.sn@pnu.edu.ph

\section{References}

American Psychiatric Association. (2013). Diagnostic and statistical manual of mental disorders $\left(5^{\text {th }}\right.$ ed.). Washington, DC: Author.

Anderson, C. M., Smith, T., \& Jovannone, R. (2018). Building Capacity to Support Students with Autism Spectrum Disorder: A Modular Approach to Intervention \& Treatment of Children.

Bailey, E. \& Montgomery, R. (2012). The Essential Guide to Asperger's Syndrome. Penguin Group (USA) Inc.

Bandura, A. (1976). The role of modeling processes in personality development. National Association for the Education of Young Children.

Bauminger- Zviely, N. (2013). Social and Academic Abilities in Children with High Functioning Autism Spectrum Disorder. London: The Guilford Press.

Cook, C. R., Gresham, L. K., Barreras, R. B., Thornton, S., \& Crews, S. D. (2008). Socials skills training for secondary students with emotional and/ or behavioral disorders: A review and analysis of the meta-analytic literature. Journal of Emotional and Behavioral Disorders, 16, 131-144.

Crooke, P., Hendrix, R., \& Rachman, J. (2007). Brief report: measuring the effectiveness of teaching social thinking to children with Asperger syndrome (AS) and high functioning autism. (HFA)Springer Science+Business Media, LLC.

Daraeea, M., Salehib, K., \& Fakhir, M. (2016). Comparison of Social Skills between Students in Ordinary and Talented Schools. Researchgate. Doi: DOI:

Gustaven, A. M. (2017). Longitudinal relationship between social skills and academic achievement in a gender perspective. Cogent education, 4(1), 1411035.

Howlin, P. (2010). Evaluating psychological treatments for children with autism-spectrum disorders. Advances in Psychiatric Treatment. 16(2), 133-140.

Macnamara, R. (2015). A Group Based Intervention for Children with Special Educational Needs: Promoting Social Skills and Communication through Shared Cooking Activities in a Mainstream Primary School. Reach, 283-20.

McMahon, C. M., Vismara, L. A., \& Solomon, M. (2012). Measuring changes in social behavior during a social skills intervention for higher-functioning children and adolescents with autism spectrum disorder. Springer Science+Business Media New York.

Majid, A. (2015). An Introduction to Communication Skills. Academia.Edu. Retrieved from https://www.edu/16862358/An_introduction_to_Communication-skills

Marshall, C. \& Rossman, G. (2016). Designing Qualitative Research Sixth Edition. California: SAGE Publication, Inc. 
INTERNATIONAL JOURNAL OF ACADEMIC RESEARCH IN BUSINESS AND SOCIAL SCIENCES

Vol. 9, No. 6, June, 2019, E-ISSN: 2222-6990 (C) 2019 HRMARS

Murdymootoo, V., Elissalde, S., Salle-Collemiche, X., Guivarch, J., Poinso, F., Tardieu, S., \& Jouve, E. (2017). Impact of an implicit social skills training group in children with autism spectrum disorder without intellectual disability: A before-and-after study. Plos ONE, 12(7), 1-18.

Neisworth, J., \& Wolfe, P. (2007). The Autism Encyclopedia. Mayland, U.S.A.:Brookes Publishing Co. Inc.

Pickard, K., \& Ingersoll, B. (2015). Brief Report: High and Low Level Initiations of Joint Attention, and Response to Joint Attention: Differential Relationships with Language and Imitation. 45(1), 262-268. doi:10.1007/s10803-014-2193-8

Rabi, N. M., Ghazali, N.H.C.M., Rohaizad, n.A.a., \& Zulkefli, M.Y.. (2018). Readiness of Pre-Service Teacher to teach Student with Special Needs through Inclusive Education Course. International Journal of Academic Research in Progressive Education and Development, 7(4), 200-210.

Silverman, C. (2012). Understanding Autism : Parents, Doctors, and the History of a Disorder. Princeton, N.J.: Princeton University Press.

Venu, V., Reddy, P. (2016). Communication Skills. Academia.Edu, 3(04). Retrieved from https://www.academia.edu/29435711/Communication_Skills

Vidal, L. A. S. (2012). Intellectual, academic and psychosocial self - care achievements among children with autism. Education Quarterly, Vol. 70 no. 1 